\title{
PERANCANGAN MODEL BISNIS CAFE ZAPATERIA
}

\author{
Peggy Hariwan \\ Inggi Silviatni \\ Administrsi Bisnis, Telkom University \\ Jl. Telekomunikasi No. 1 Ters. Buahbatu - Dayeuh Kolot \\ email:peggyhariwan@gmail.com
}

\begin{abstract}
The aim of this research is to plan business model for Zapateria's cafe using BMC framework. Zapateria will be presented as example of development service cafe system which offer coziness, the simplicity of eat and shop which never been offered by other cafe. Moreover, the data exist showed the sum of people who visit Bandung for culinary and shopping with the number increase time to time. Those things are the reasons why this research made which are business model for cafe and shoes shop at one blow.

Knowing the responses from the prospect of customers, which are adults, tourists, community, and shoes lover is the main aim of this research as a support in making business model plan that will be established. Qualitative method is the methodology used by the research which also triangulasi theory which are practitioners, expertise of cafe business, and experts in business field as data source. Direct interview to all source become technique to gather the data. The results analyzed and become indicator in empathy map.

From the results of interview held show there are disappointment for miss delivery order and willingness of improvement for service offered by the exist cafe in Bandung by music performance in weekend and using gadget for integrated order from customer to the kitchen to reduce mistaken order and missing order. Final plan made from this research be expected can help development of business idea in Zapateria and other cafe.
\end{abstract}

Keywords: Business Model, Business Model Canvas (BMC), Cafe, and Shoes 


\section{PENDAHULUAN}

\section{Latar Belakang Penelitian}

Pada mulanya budaya minum kopi di Indonesia merupakan kebiasaan yang dilakukan oleh pemerintah Belanda pada jaman tanam paksa. Namun, seiring perkembangannya masyarakat Indonesia pun mulai gemar meminum kopi. Kehadiran kedai kopi atau cafe di Indonesia, mengubah gaya hidup masyarakat Indonesia dalam meminum kopi. Meminum kopi tidak lagi menjadi kebiasaan orang dewasa hanya untuk mengurangi kantuk, tetapi juga anak muda baik pria maupun wanita. Dulu kedai kopi atau cafe identik dengan tempat yang kurang nyaman, tidak terlihat menarik dengan suasana yang monoton. Kini cafe identik dengan tempat yang nyaman, suasana yang cozy, fasilitas yang lengkap seperti lounge,bar, AC (Air Conditioner), Wi-Fi, bahkan mulai bermunculan cafe dengan desain interior yang unik yang belum pernah ada sebelumnya. Sehingga tidak aneh apabila saat ini masyarakat merasa nyaman untuk menghabiskan banyak waktubersama kerabat di kedai kopi atau cafe.

Dengan berbagai sarana dan prasarana yang ditawarkan oleh cafe saat ini, masyarakat menjadikan cafe sebagai tempat yang nyaman untuk melakukan berbagai aktivitas seperti tempat untuk bertemu dengan sahabat, teman lama, keluarga, ataupun kolega bisnis. Tidak jarang konsumen cafe datang untuk mengerjakan tugas kuliah, tugas kantor, atau sekedar memperoleh informasi terbaru dengan memanfaatkan fasilitas jaringan Wi-Fi yang disediakan oleh cafe tersebut, sambil mencicipi berbagai jenis minuman dan makanan yang ditawarkan.

Bandung sebagai salah satu simbol wisata kuliner, tidak ketinggalan dalam perkembangan bisnis cafe. Sejak tahun 2006 di bandung mulai banyak bermunculan kedai kopi lokal yang sejenis dengan kedai kopi asing seperti Starbucks Coffee, Gloria jean's Coffee, dan The Coffee Bean and Tea Leaf. Kedai kopi ini dibangun untuk memenuhi kebutuhan masyarakat akan budaya minum kopi dengan sarana dan prasarana yang sangat memberikan kenyamanan bagi konsumennya, seperti tempat duduk yang nyaman serta kemudahan akses internet.

Menurut Kotler (dalam Tjiptono et al., 2006:28) agar dapat mengikuti perkembangan dan unggul dalam persaingan, perusahaan dituntut untuk dapat memberikan kepuasan kepada pelanggannya dengan memberikan suatu produk atau jasa dengan mutu yang lebih baik dan harga lebih murah serta kepastian ketersediaan. Suatu usaha juga akan mengalami tantangan tersendiri dan dituntut mempunyai kelebihan yang tidak dimiliki pesaing. Hal ini berlaku di semua jenis bisnis terlebih industri yang merabah seperti industri kuliner dan fashion. Oleh karena itu, peneliti memiliki ide dalam perencanaan bisnis cafe yang belum ada sebelumnya yakni penggabungan antara bidang kuliner dan fashion (sepatu).

Sepatu dipilih karena sepatu termasuk unsur penting pembentuk self image seseorang. Membuat penggunanya makin percaya diri dan nyaman ketika berinteraksi dengan orang lain. Jika self imagenya positif, maka akan berdampak pada terbangunnya konsep diri yang positif pula. Dengan konsep diri positif, maka individu tersebut akan bahagia dengan hidup yang dijalaninya.

Apalagi pada momen pesta atau acara sosial yang membuat penampilan mereka terekspos oleh banyak orang. Keberadaan sepatu jadi penting untuk dipadukan dengan busana yang dipakai. Ungkapan ini dikemukan oleh Linda O'Keeffe dalam sebuah bukunya yang berjudul Shoes. 
Dalam buku kecil namun menarik isinya tersebut, O'Keeffe mengungkapkan bagaimana sepatu wanita punya banyak hal esensial dalam kehidupan yang bisa digali. Mulai dari ranah psikologi, folklore (cerita rakyat), hingga sejarah sosial, dapat dikupas secara mendalam. Berkaitan dengan folklore, di dalam bukunya O'Keeffe menyatakan keberadaan sepatu wanita dapat dilihat pada dongeng Cinderella. Kisah fiktif terkenal itu menceritakan bagaimana sepasang sepatu kaca dapat mengubah nasib seorang wanita secara drastis. Dari wanita terjajah dan terhina, menjadi wanita yang dipuja dan didamba semua orang.

Ada pun perbincangan mengenai sejarah sepatu dalam konteks sosial, akan mengarah pada bagaimana awal mulanya keberadaan sepatu dan perkembangannya hingga menjadi bagian dari fashion tak terpisahkan. Salah satu sumber lengkap untuk melihat hal tersebut adalah dengan mengunjungi berbagai museum sepatu wanita yang tersebar di berbagai kota di dunia. Yaitu Clarks Museum, Bally Shoe Museum, The Bata Shoe Museum, Charles Jourdan Museum, dan Museo Salvatore Ferragamo.

Seperti yang diketahui, Bandung adalah tempat bagi mereka yang mencari sensasi berkuliner dan belanja, serta menilai kepuasan dalam melewati kehidupan sosial, berkeluarga dan kebersamaan. Kota Bandung sebagai ibu kota provinsi Jawa Barat secara geografis terletak di tengah-tengah provinsi Jawa Barat dan mempunyai nilai strategis terhadap daerah-daerah di sekitarnya terutama DKI Jakarta. Berkat dataran tinggi dan gunung-gunung di sekelilingnya, Kota Bandung memiliki hawa yang sejuk dan panorama alam yang indah.

Kota Bandung juga merupakan pusat perkembangan dan industri, karena itu Bandung juga mempunyai daya tarik untuk para kaum urban untuk mencari pekerjaan. Banyaknya pendatang dari berbagai daerah ke Kota Bandung untuk menuntut ilmu atau mencari pekerjaan, menjadikan penduduk Kota Bandung sangat heterogen. Pada Tahun 2012, Kota Bandung memiliki penduduk sebanyak 2.455.517 jiwa (BPS Kota Bandung 2012), dengan laju pertumbuhan penduduk 1,26\% dan tingkat kepadatan penduduk mencapai 14.676 orang per km2. Heteroginitas masyarakat Kota Bandung tersebut selain merupakan tantangan bagi Kota Bandung dalam mengelola jumlah penduduk yang besar, juga memberi peluang bagi perkembangan khasanah kekayaan kuliner nusantara di Kota Bandung yang dapat dimanfaatkan sebagai daya tarik destinasi wisatawan dari luar Bandung khususnya dari Ibukota DKI Jakarta. 
Tabel 1Penduduk Kota Bandung Menurut Kelompok Umur dan Jenis Kelamin Tahun 2012

\begin{tabular}{|c|c|c|c|c|}
\hline \multicolumn{2}{|c|}{$\begin{array}{l}\text { KEILOMFOK UMUR } \\
\text { AGE GROUP }\end{array}$} & \multirow{3}{*}{$\begin{array}{c}\text { LAKI-I_AKI } \\
\text { MALE } \\
{[2]} \\
13.292\end{array}$} & \multirow{3}{*}{$\begin{array}{c}\text { PEREMPUAN } \\
\text { FEMALE } \\
{[3]} \\
18.894\end{array}$} & \multirow{3}{*}{$\begin{array}{c}\text { JUMI_AH } \\
\text { TOTAL } \\
{[4]} \\
32.186\end{array}$} \\
\hline & 11 & & & \\
\hline 1 & $0-4$ & & & \\
\hline 2 & $5-9$ & 13.631 & 15.536 & 29,167 \\
\hline 3 & $10-14$ & 21.211 & 23.157 & 44.368 \\
\hline 4 & $15-19$ & 27.062 & 28.446 & 55.508 \\
\hline 5 & $20-24$ & 46.000 & 43.169 & 89.169 \\
\hline 6 & $25-29$ & 60.051 & 59.462 & $119 \leq 513$ \\
\hline 7 & $30-34$ & 70.684 & 72.118 & 142.802 \\
\hline 8 & $35-39$ & 86.816 & 84.832 & 171.648 \\
\hline 9 & $40-44$ & 101.646 & 96.429 & 198.075 \\
\hline 10 & $45-49$ & 117.290 & 108.595 & 225.885 \\
\hline 11 & $50-54$ & 132.013 & 121.802 & 253.815 \\
\hline 12 & $55-59$ & 130.003 & 123.107 & 253.110 \\
\hline 13 & $60-64$ & 111.269 & 113.951 & 225220 \\
\hline 14 & $65-69$ & 97.629 & 94.144 & 191.773 \\
\hline 15 & $70-74$ & 108.813 & 102.547 & 211.360 \\
\hline 16 & 75 Keatas & 108.712 & 103.206 & 211.918 \\
\hline & $\begin{array}{l}\text { nath } \\
\text { tal }\end{array}$ & 1.246 .122 & 1.209 .395 & 2455.517 \\
\hline
\end{tabular}

Sumber: BPS Kota Bandung

Selain terkenal dengan daerah wisata belanja, Bandung juga terkenal sebagai pusat kuliner, baik kuliner lokal maupun internasional. Bandung memiliki tempat kuliner yang eksklusif, mewah dan mahal sampai tempat kuliner yang unik dan tradisional, begitu juga tempat kuliner nongkrong anak muda sampai tempat kuliner di pinggiran jalan semuanya tersedia di Kota Bandung.

Maka dari itu Kota Bandung merupakan salah satu kota wisata yang digemari bidang kuliner dan fashionnya, terbukti dengan adanya kenaikan yang signifikan pada kunjungan wisatawan ke Bandung setiap tahunnya. Bandung memiliki berbagai pilihan kuliner unik dan fashion yang beragam sehingga wisatawan tidak pernah bosan untuk berkunjung ke Bandung, terlebih lagi disaat weekend dan libur panjang. Kenaikan jumlah wisatawan ke Kota Bandung diiringi dengan meningkatnya jumlah cafe atau tempat makan sejenis lainnya. 
Tabel 2Jumlah Wisatawan Mancanegara dan Nusantara ke Objek Wisata Kota BandungTahun 2007 2011

\begin{tabular}{cccc}
\hline Tahun & Jumlah Wisman & Tahun & Jumlah Wisnus \\
\hline $\mathbf{2 0 0 7}$ & 137.268 & 2007 & 2.420 .105 \\
\hline $\mathbf{2 0 0 8}$ & 150.995 & 2008 & 2.662 .115 \\
\hline $\mathbf{2 0 0 9}$ & 185.076 & 2009 & 7.515 .255 \\
\hline $\mathbf{2 0 1 0}$ & 228.449 & 2010 & 4.951 .439 \\
\hline $\mathbf{2 0 1 1}$ & 225.585 & 2011 & 6.487 .239 \\
\hline
\end{tabular}

Sumber: Dinas Kebudayaan dan Pariwisata Kota Bandung

Dari data diatas, dapat disimpulkan bahwa terdapat peningkatan jumlah wisatawan ke Bandung dari tahun ke tahun, hal ini dilihat sebagai peluang bagi pengusaha untuk menciptakan bisnis baru yang dicari wisatawan. Melihat kondisi persaingan yang semakin ketat, setiap perusahaan perlu meningkatkan kekuatan yang ada dalam perusahaannya dengan cara memunculkan faktor pembeda atau keunikan yang dimiliki perusahaan dibandingkan dengan pesaing untuk dapat menarik konsumen. Bermunculannya restoran-restoran baru di Bandung yang semakin banyak membuat persaingan menjadi ketat, mendorong usaha baru atau usaha yang sudah ada harus memiliki daya tarik yang berbeda dari yang lain.

Tabel 3 Usaha Cafe di Kota Bandung

\begin{tabular}{|c|c|c|}
\hline Tahun & Jumlah Cafe & Presentase Kenaikan \\
\hline 2008 & 156 & \\
\hline 2009 & 186 & $19,23 \%$ \\
\hline 2010 & 191 & $2,68 \%$ \\
\hline 2011 & 196 & $2,61 \%$ \\
\hline 2012 & 235 & $19,89 \%$ \\
\hline
\end{tabular}

Sumber ; http://bandung.go.id 
Tabel 3 memperlihatkan bahwa dari tahun 2008 sampai 2012 terdapat peningkatan jumlah cafe yang mengakibatkan persaingan dalam bidang restoran di Kota Bandung meningkat juga, sehingga perusahaan harus mempunyai ciri khas sendiri untuk dapat bersaing dengan perusahaan yang menawarkan produk sejenis. Oleh karena itu penulis menuangkan ide dalam pembuatan bisnis baru di bidang kuliner dan fashion yang belum pernah ada di Kota Bandung sebelumnya pada sebuah penelitian yang berjudul "Perancangan Model Bisnis Cafe Zapateria".

\section{Rumusan Masalah Penelitian}

Bagaimana rancangan desain atau model bisnis Zapateria menggunakan toolBusiness Model Canvas.

\section{Pernyataan tujuan}

Tujuan dari penelitian ini adalah untuk menyiapkan rancangan desain atau model bisnis Zapateria dengan menggunakan Business Model Canvas untuk menjelaskan model bisnis ini.

\section{LANDASAN TEORI}

\section{Tinjauan Pustaka}

Bisnis Model Kanvas dan Peta Empati merupakan hal penting untuk membangun sebuah bisnis model.Peta empati sendiri merupakan alat bantu visual yang membantu kita untuk dapat membuat profil pelanggan dengan cara yang sangat mudah dan sederhana. Peta empati sangat penting karena banyak perusahaan berinvestasi sangat besar dalam riset pasar, meskipun pada saat mendesain produk, layanan, dan model bisnis sering kali mengabaikan perspektif pelanggan. Desain model bisnis yang baik akan menghindari kesalahan seperti ini.

\section{Model Bisnis Kanvas}

Menurut Eisenmann (2002:12), Model Bisnis adalah hipotesis tentang bagaimana perusahaan menghasilkan uang dalam jangka panjang: apa yang perusahaan akan jual, dan kepada siapa, bagaimana perusahaan akan mengumpulkan pendapatan, teknologi apa yang akan digunakan, kapan perusahaan akan bergantung pada mitra bisnisnya serta bagaimana dengan hal biaya. Definisi lain mengenai model bisnis yaitu "Sebuah model bisnis menggambarkan dasar pemikiran tentang bagaimana organisasi menciptakan, memberikan, dan menangkap nilai." (Alexander Osterwalder dan Yves Pigneur, 2012:14).

Menurut Alexander Osterwalder dan Yves Pigneur dalam bukunya Business Model Generation ada sembilan blok bangunan dasar pada sebuah bisnis model yang memperlihatkan cara berpikir tentang bagaimana sebuah perusahaan menghasilkan uang, gabungan kesembilan blok tersebut disebut Business Model Canvas (BMC). Kesembilan blok tersebut mencangkup empat bidang utama pada suatu bisnis, yaitu pelanggan, penawaran,

infrastruktur, dan kelangsungan finansial (Alexander Osterwalder dan Yves Pigneur, 2012:15) 


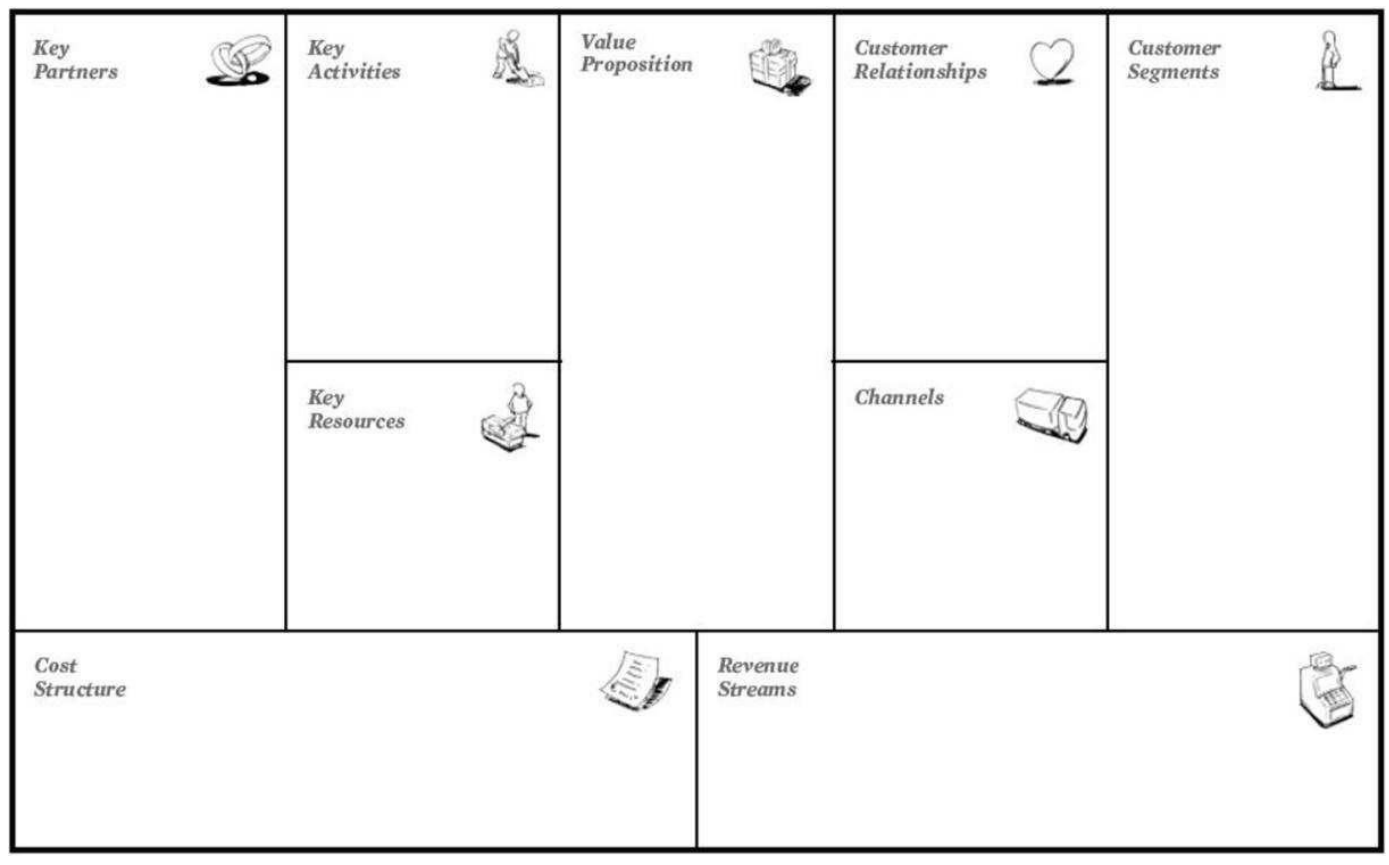

Gambar 1 Model Bisnis Kanvas

Sumber: Alexander Osterwalder dan Yves Pigneur (2012:44)

\subsection{Kerangka Pemikiran}

Perkembangan dunia bisnis membuat banyaknya ide-ide baru yang bermunculan sebagai bentuk antusiasme dari dunia bisnis itu sendiri. Dari berbagai macam ide yang muncul, terdapat tools yang dapat mewadahi ide-ide tersebut untuk dilakukan perancangan bisnis awal. Dan tools Business Model Canvas menjadi salah satu pilihan untuk membuat rancangan bisnis awal dari ide-ide tersebut. Rancangan bisnis awal yang muncul akan dituangkan kedalam sebuah pertanyaan yang terdapat pada tools Empaty Map dan kemudian hasil jawaban dari pertanyaan yang berasal dari empaty map dapat mempengaruhi rancangan bisnis awal yang sudah tercantum dalam tools Business Model Canvas. Hasil dari rancangan yang telah dibentuk dengan tools Business Model Canvasakan menjadi acuan untuk menentukan strategi bisnis.

Peneliti akan melakukan rancangan bisnis awal cafe Zapateria dengan menggunakan tools Business Model Canvas serta empaty map sebagai tools untuk mengetahui pandangan dasar dari orang-orang yang memilki hubungan langsung dengan lingkungan bisnis cafe Zapateria dimana pandangan tersebut akan berguna bagi rancangan bisnis cafe Zapateria.

Adapun kerangka pemikiran dari penjelasan di atas sebagai berikut: 


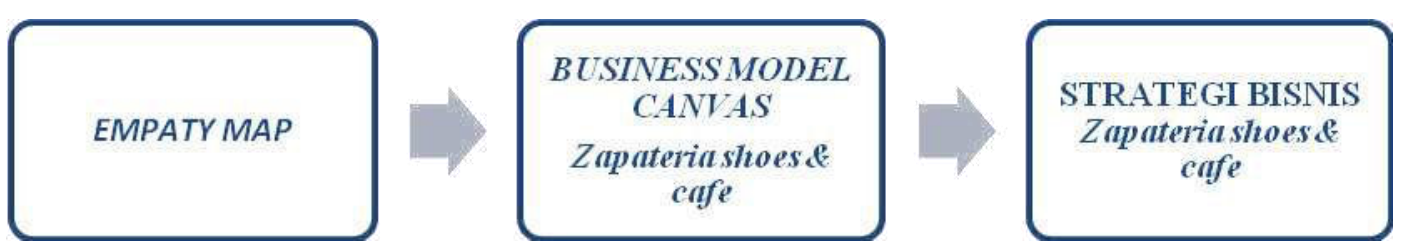

Gambar 2 Kerangka Pemikiran

\subsection{Hipotesis}

Menurut Ali (dalam Tukiran et al., 2011:24) mengartikan hipotesis adalah rumusan jawaban sementara yang harus diuji melalui kegiatan penelitian. Hipotesis juga dapat diartikan penjelasan tentatif (sementara) tentang tingkah laku, fenomena (gejala), atau kejadian yang akan terjadi, bisa juga mengenai kejadian yang sedang berjalan menurut Rudeffendi dan Achmad Sanusi (dalam Tukiran et al., 2011:25)

Berdasarkan rancangan pada bisnis sejenis dan kerangka pemikiran yang telah dikemukakan, maka dapat diajukan hipotesis rancangan bisnis awal cafe Zapateria dengan pivoting sebagai berikut: 
Gambar 3. Hipotesis Rancangan Awal DesignZapateriashoes \&café (Menggunakan Model Bisnis Kanvas)

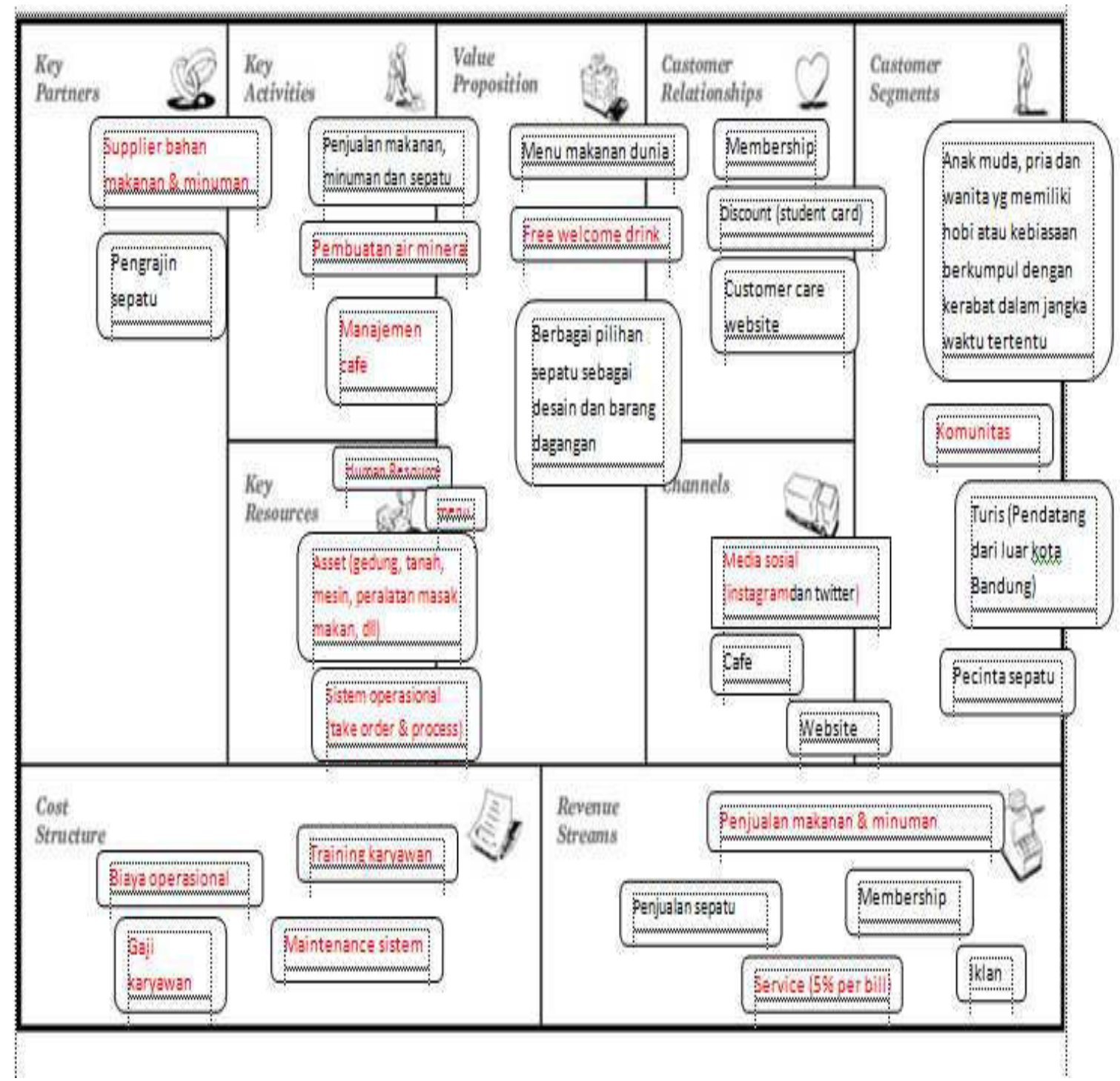




\section{METODE PENELITIAN}

\section{Metode Seleksi}

Pengumpulan data yang dilakukan peneliti hanya bersifat data pendukung. Metode pengumpulan data yang dilakukan pada penelitian ini dibagi menjadi dua bagian, pada penelitian kualitatif peneliti menggunakan metode pengumpulan data wawancara dan pada penelitian kuantitatif menggunakan metode pengumpulan data kuesioner.

\section{Pengumpulan Data}

Secara garis besar, pengumpulan data pendukung diperlukan untuk melihat adanya kemungkinan dari penelitian model bisnis Zapateria baik primer dan sekunder.

\section{A. Data Primer}

Data primer merupakan data yang diperoleh langsung dari sumbernya atau objek penelitian.Data primer biasanya diperoleh dengan wawancara langsung kepada objek atau dengan pengisian kuesioner (daftar pertanyaan) yang dijawab oleh objek penelitian. (Suharyadi \& Purwanto, 2009:14). Pemenuhan data primer dilakukan dengan melakukan survei lapangan dengan memberikan pertanyaan kepada potential consumer sehingga kemungkinan dari sisi produk dan segmen pasar terlihat.

B. Data Sekunder

Data sekunder merupakan data yang sudah diterbitkan atau digunakan pihak lain. Contoh data sekunder adalah data yang diambil dari koran, majalah, jurnal, dan publikasi lainnya. (Suharyadi \& Purwanto, 2009:14).

Data sekunder yang digunakan dalam penulisan rencana bisnis ini bersumber dari literatur rencana bisnis cafe yang sudah ada.

\section{Pengukuran dan Defisini Operasional Variabel}

Menurut Sugiyono (2008:38), variabel penelitian pada dasarnya adalah segala sesuatu yang berbentuk apa saja yang ditetapkan oleh peneliti untuk dipelajari sehingga diperoleh informasi tentang hal tersebut, kemudian ditarik kesimpulannya. 
Tabel 4 Variabel Operasional

\begin{tabular}{|c|c|c|}
\hline Variabel & Definisi & Dimensi \\
\hline Peta Empati & \begin{tabular}{lr}
\multicolumn{1}{c}{ Sebuah alat bantu } \\
pembuat profil pelanggan yang \\
sederhana, yang & membantu \\
anda berjalan & melampaui \\
karakteristik & demografi \\
pelanggan dan \\
mengembangkan pemahaman \\
yang lebih baik tentang \\
lingkungan, r perilaku, \\
kepedulian, dan aspirasi.
\end{tabular} & $\begin{array}{l}\text { 1. Apa yang dilihatnya? (see?) } \\
\text { 2. Apa yang didengarnya? } \\
\text { (hear?) } \\
\text { 3. Apa yang benar-benar } \\
\text { dipikirkan dan dirasakannya? } \\
\text { (think\& feel?) } \\
\text { 4. Apa yang dikatakan dan } \\
\text { dilakukannya? (say\& do?) } \\
\text { 5. Sakit hati apa yang dirasakan } \\
\text { pelanggan? (pain) } \\
\text { 6. Apa saja perolehan } \\
\text { pelanggan? (gain) }\end{array}$ \\
\hline
\end{tabular}

Sumber: data diolah peneliti

\section{Metode Analisis Data}

Metode penelitian kualitatif, menurut Creswell ada lima strategi kualitatif yang salah satunya digunakan oleh peneliti adalah studi kasus. Studi kasus merupakan strategi penelitian yang didalamnya peneliti menyelidiki secara cermat suatu program, peristiwa, aktivitas, proses, atau sekelompok individu (Creswell, 2009:19-21). Pendekatan triangulasi digunakan untuk menguji keabsahan data dan menemukan kebenaran objektif sesungguhnya.Strategi ini sangat tepat untuk menganalisis kejadian tertentu disuatu tempat tertentu dan waktu tertentu pula.

\section{A. Emphaty Map}

Cara yang baik untuk memulai adalah dengan menggunakan peta empati, yaitu pembuat profil pelanggan yang sederhana, yang membantu anda berjalan melampaui karakteristik demografi pelanggan dan mengembangkan pemahaman yang lebih baik tentang lingkungan, perilaku, kepedulian, dan aspirasi. Dengan alat ini kita bisa menemukan model bisnis yang lebih kuat karena profil pelanggan memandu perancangan proposisi nilai yang lebih baik, cara yang lebih nyaman dalam menjangkau pelanggan, dan hubungan pelanggan yang lebih baik (Alexander Osterwalder dan Yves Pigneur, 2012:131).

Peta empati merupakan alat bantu visual yang dikembangkan oleh perusahaan berpikir visual bernama XPLANE (Alexander Osterwalder dan Yves Pigneur, 2012:131). Alat bantuvisual satu halaman ini terdiri dari enam kotak yang terdiri dari berbagai pertanyaan yang memungkinkan perusahaan untuk lebih memahami dengan lebih baik apa yang benar-benar diinginkan oleh pelanggan. 


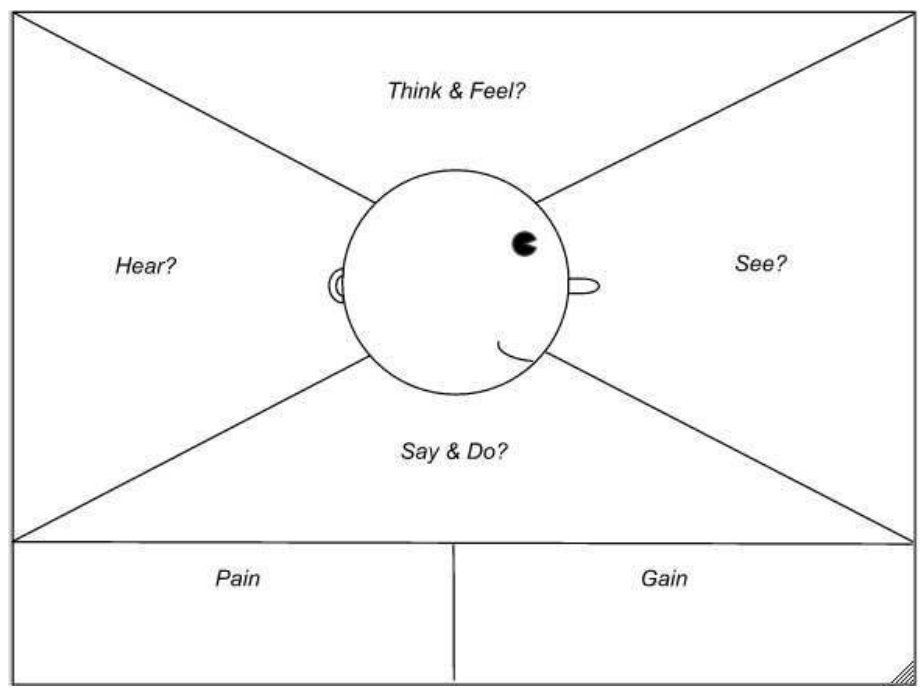

Gambar 4 Peta Empati

Sumber: Alexander Osterwalder dan Yves Pigneur (2012:130)

Cara menggunakan Peta Empati sangat mudah. Mulailah dengan memberi pelanggan ini nama yang dilengkapi beberapa karakteristik demografi, seperti pendapatan, status pernikahan, dan lain-lain. Kemudian, dengan mengacu pada gambar yang ada dibawah ini, gunakan flip chart atau papan tulis untuk membuat profil pelanggan yang mendapat nama baru dengan bertanya dan menjawab enam pertanyaan berikut (Alexander Osterwalder dan Yves Pigneur, 2012:131).

\section{Tabel 5}

\section{Pertanyaan Peta Empati}

\begin{tabular}{|c|l|}
\hline Apa yang dilihatnya? (See?) & - Seperti apa tampaknya? \\
$\begin{array}{c}\text { Jelaskan apa yang dilihat } \\
\text { pelanggan dalam lingkungannya }\end{array}$ & - Siapa yang mengelilinginya? \\
& - Siapa teman-temannya? \\
\hline $\begin{array}{c}\text { Apa yang didengarnya? } \\
\text { (Hear?) }\end{array}$ & $\begin{array}{l}\text { - Apa yang dikatakan teman- temannya? } \\
\text { Pasangannya? }\end{array}$ \\
$\begin{array}{c}\text { Menjelaskan bagaimana } \\
\text { lingkungan memengaruhi } \\
\text { pelanggan }\end{array}$ & $\begin{array}{l}\text { - Siapa yang benar-benar } \\
\text { memengaruhinya, dan bagaimana? }\end{array}$ \\
\hline $\begin{array}{c}\text { Apa yang benar-benar } \\
\text { dipikirkan dan dirasaknnya? } \\
\text { (Think \& Feel?) }\end{array}$ & $\begin{array}{c}\text { - Apa yang benar-benar penting untuknya } \\
\text { (yang tidak dikatakannya secara } \\
\text { terbuka)? }\end{array}$ \\
\hline
\end{tabular}




\begin{tabular}{|c|c|}
\hline $\begin{array}{l}\text { Mencoba menguraikan apa yang } \\
\text { ada dibenak pelanggan }\end{array}$ & $\begin{array}{l}\text { - Bayangkan emosinya. Apa yang } \\
\text { menggerakkannya? } \\
\text { - Apa yang dapat membuatnya terbangun } \\
\text { di malam hari? } \\
\text { - Cobalah menggambarkan mimpi-mimpi } \\
\text { dan aspirasinya. }\end{array}$ \\
\hline $\begin{array}{c}\text { Apa yang dikatakan dan } \\
\text { dilakukannya? (Say and Do?) } \\
\text { Membayangkan apa yang } \\
\text { mungkin dikatakan pelanggan, } \\
\text { atau bagaimana perilakunya di } \\
\text { depan umum }\end{array}$ & $\begin{array}{l}\text { - Apa sikapnya? } \\
\text { - Apa yang dapat dikatakannya kepada } \\
\text { orang lain? } \\
\text { - Berikan perhatian yang memadai untuk } \\
\text { potensi komflik antara apa yang } \\
\text { mungkin dikatakan pelanggan dan apa } \\
\text { yang mungkin benar-benar dipikirkan } \\
\text { atau dikatakannya. }\end{array}$ \\
\hline $\begin{array}{c}\text { Sakit hati apakah yang } \\
\text { dirasakan pelanggan? (Pain) }\end{array}$ & $\begin{array}{l}\text { - Apakah frustasi terbesarnya? } \\
\text { - Risiko apa yang ditakutinya? }\end{array}$ \\
\hline $\begin{array}{c}\text { Apa saja perolehan pelanggan? } \\
\text { (Gain) }\end{array}$ & $\begin{array}{l}\text { - Apa yang benar-benar ingin dicapainya? } \\
\text { - Bagaimana ia mengukur kesuksesan? } \\
\text { - Pikirkan beberapa strategi yang dapat } \\
\text { digunakannya untuk mencapai tujuan. }\end{array}$ \\
\hline
\end{tabular}

Sumber: Alexander Osterwalder dan Yves Pigneur (2012:131)

\section{B. Triangulasi}

Triangulasi adalah teknik pengumpulan data yang bersifat menggabungkan dari berbagai teknik pengumpulan data dan sumber data yang telah ada (Sugiyono, 2012: 241). Penggunaan teknik triangulasi akan lebih meningkatkan kekuatan data yang akan diperoleh karena data yang didapat tidak hanya dari satu teknik atau satu sumber pengumpulan data.

Triangulasi sumber data merupakan triangulasi yang mendapatkan data dari sumber yang berbeda-beda dengan teknik yang sama. Dalam triangulasi sumber pengumpulan data dilakukan dengan cara wawancara kualitatif, dimana peneliti dapat melakukan face to face interview (wawancara langsung) dengan partisipan, mewawancarai mereka dengan telepon, atau terlibat langsung (Creswell, 2009: 267). Proses wawancara dilakukan untuk mendapatkan data dari narasumber. Teknik wawancara yang digunakan dalam penelitian ini adalah teknik wawancara yang terstruktur, maksudnya adalah proses wawancara dilakukan secara terencana. Gambar dibawah menjelaskan triangulasi sumber pengumpulan data dengan mendapatkan data melalui wawancara dari sumber yang berbeda - beda dengan teknik yang sama (Sugiyono, 2012: 241). 
Peggy Hariwan

Inggi Silviatni

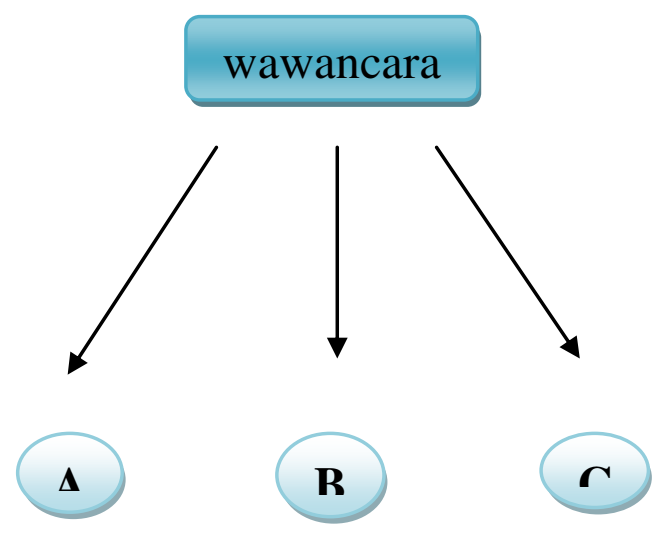

Gambar 5

\section{Triangulasi Sumber Pengumpulan Data}

Data yang didapat dari hasil wawancara yang bertujuan untuk memeriksa keabsahan data selanjutnya akan dilakukan coding, melakukan pemilihan data yang relevan dengan pokok pembicaraan. Data yang telah dikelompokkan tersebut oleh peneliti kemudian dipahami secara utuh dan ditemukan poin-poin yang peneliti gunakan sebagai indikator yang akan dicocokkan dengan indikator pada setiap pertanyaan empaty map.

\section{Praktisi Usaha}

Cafe
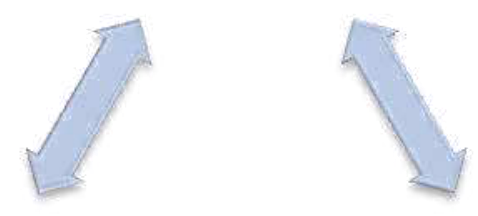

\section{\begin{tabular}{|c|} 
Calon \\
Pelanggan
\end{tabular}}

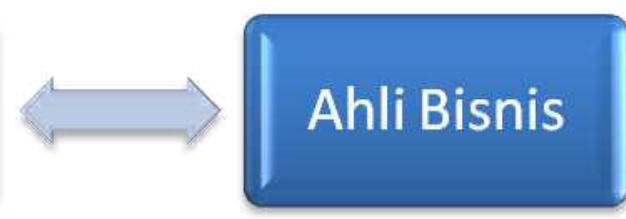

\section{Gambar 6 Triangulasi Sumber Data}

Sumber data triangulasi Pelaku Usaha Cafe didapatkan dengan mendatangi tempat makan yang memiliki brand image yang baik di masyarakat, berdasarkan berita yang terdapat pada surat kabar ataupun media internet. Data calon pelanggan didapatkan dengan menemui mereka di cafe atau setelah mereka mengunjungi sebuah cafe. Sumber data Ahli Bisnis peneliti ambil dari mereka yang peneliti anggap memahami betul mengenai dunia bisnis yakni lulusan Master of Business Administration Institut Teknologi Bandung dan berkecimpung langsung dalam dunia bisnis, dalam hal ini peneliti tunjuk seorang dosen bisnis yang memiliki title tersebut dan orang yang berada dalam naungan komunitas bisnis Tangan Di Atas. 


\section{HASIL DAN PEMBAHASAN}

\section{Indikator Peta Empati}

Berikut hasil wawancara dari para informan triangulasi:

Tabel 6 Indikator Peta Empati berdasarkan Informan Triangulasi

\begin{tabular}{|c|c|c|c|c|c|}
\hline \multirow[t]{2}{*}{ No } & \multirow{2}{*}{$\begin{array}{l}\text { Pertanyaan } \\
\text { Peta Empati }\end{array}$} & \multicolumn{4}{|c|}{ Indikator } \\
\hline & & & Praktisi Usaha & Ahli & Segmen Pelanggan \\
\hline 1 & $\begin{array}{c}\text { Apa yang } \\
\text { dilihatnya? } \\
\text { (see) }\end{array}$ & $\frac{1}{>}$ & $\begin{array}{l}\text { Persaingan yang } \\
\text { semakin ketat dalam } \\
\text { setiap lini pelayanan } \\
\text { Desain interior unik } \\
\text { untuk pengambilan } \\
\text { foto } \\
\text { Diskon pelajar } \\
\text { Diskon pada jam } \\
\text { tertentu } \\
\text { Rasa makanan tidak } \\
\text { terlalu diperhatikan, } \\
\text { prioritas utama } \\
\text { memiliki spot untuk } \\
\text { foto Kesalahan pesanan }\end{array}$ & 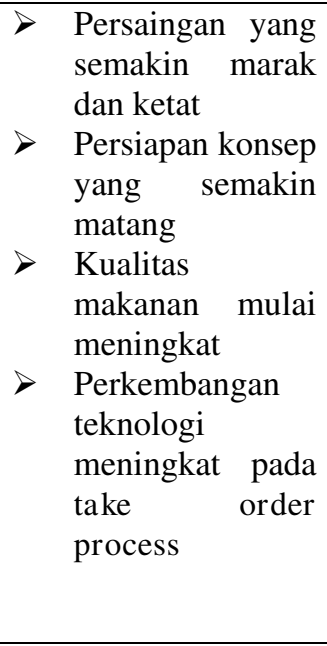 & 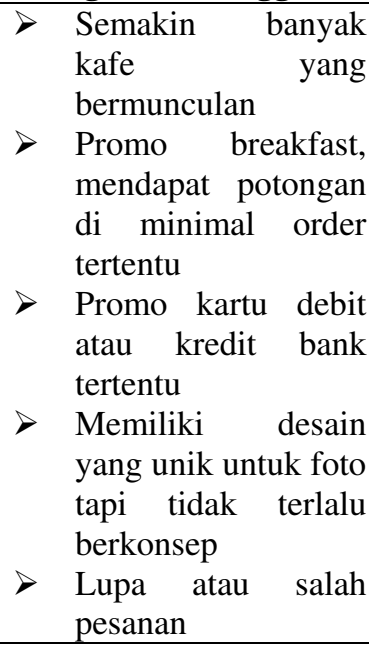 \\
\hline 2 & $\begin{array}{c}\text { Apa yang } \\
\text { didengarnya? } \\
\text { (hear) }\end{array}$ & $>$ & $\begin{array}{l}\text { Menarik pelanggan } \\
\text { melalui media sosial } \\
\text { Promosi gratis } \\
\text { melalui path } \\
\text { Mulai bermunculan } \\
\text { kafe rang } \\
\text { bekerjasama atau } \\
\text { berbagi tempat } \\
\text { dengan bidang usaha } \\
\text { lain seperti distro } \\
\text { atau barbershop } \\
\text { tetapi belum ada } \\
\text { kafe rem } \\
\text { menerapkan dua } \\
\text { sumber pendapatan } \\
\text { berbeda sekaligus } \\
\text { dalam satu konsep }\end{array}$ & $\begin{array}{l}\text { Media sosial } \\
\text { sangat } \\
\text { berpengaruh } \\
\text { Menawarkan } \\
\text { konsep bukan } \\
\text { makanan } \\
\text { Kafe dengan } \\
\text { gerai sepatu } \\
\text { dapat } \\
\text { memberikan } \\
\text { kemudahan bagi } \\
\text { orang } \\
\text { bermobilitas } \\
\text { tinggi }\end{array}$ & $\begin{array}{l}\text { Mengetahui } \\
\text { beberapa kafe dari } \\
\text { media sosial seperti } \\
\text { instagram dan path } \\
\text { Perlu konsep yang } \\
\text { benar-benar matang } \\
\text { dan menarik } \\
>\quad \text { Sosok yang } \\
\text { berkunjung sangat } \\
\text { berpengaruh } \\
\text { Kafe berkonsep } \\
\text { sepatu belum ada } \\
\text { diterapkan di kafe di } \\
\text { Bandung, cukup } \\
\text { unik dan konsepnya } \\
\text { jelas }\end{array}$ \\
\hline 3 & $\begin{array}{c}\text { Apa yang } \\
\text { dipikirkan dan } \\
\text { dirasakannya? } \\
\text { (think and feel) }\end{array}$ & & $\begin{array}{l}\text { Sistem pelayanan } \\
\text { yang diterapkan } \\
\text { masih harus terus } \\
\text { dikembangkan dan } \\
\text { ditingkatkan untuk } \\
\text { kepuasan } \\
\text { Rasa makanan } \\
\text { masih harus } \\
\text { ditingkatkan, } \\
\text { kebanyakan pelaku } \\
\text { usaha tidak terlalu } \\
\text { memprioritaskan } \\
\text { mengenai hal ini } \\
\text { Kafe yang memiliki } \\
\text { konsep tersendiri } \\
\text { dirasa dapat menjadi }\end{array}$ & 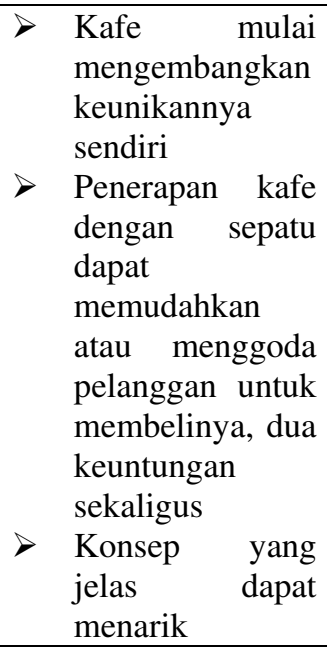 & 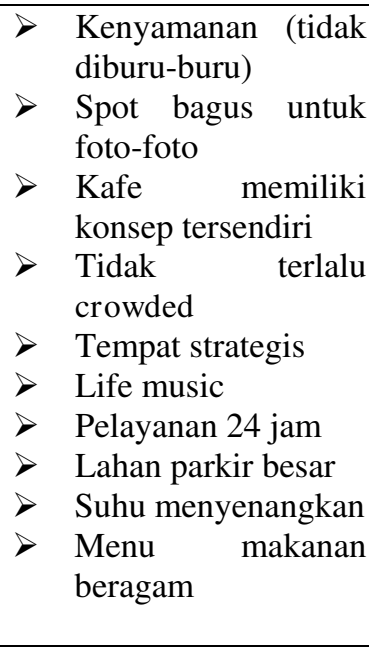 \\
\hline
\end{tabular}




\begin{tabular}{|c|c|c|c|c|c|c|}
\hline & & & $\begin{array}{l}\text { nilai tambah dan } \\
\text { mempunyai } \\
\text { keunikan sendiri } \\
\text { Tidak terlalu } \\
\text { crowded, crowded } \\
\text { tapi teratur } \\
\text { Good ambience }\end{array}$ & $>$ & $\begin{array}{l}\text { pelanggan } \\
\text { Ambience harus } \\
\text { dijaga agar } \\
\text { pelanggan } \\
\text { merasa nyaman } \\
\text { dan betah } \\
\text { Tambahan life } \\
\text { music bisa } \\
\text { menjadi } \\
\text { ketertarikan }\end{array}$ & \\
\hline 4 & $\begin{array}{c}\text { Apa yang } \\
\text { dikatakan dan } \\
\text { dilakukannya? } \\
\text { (say and do) }\end{array}$ & & 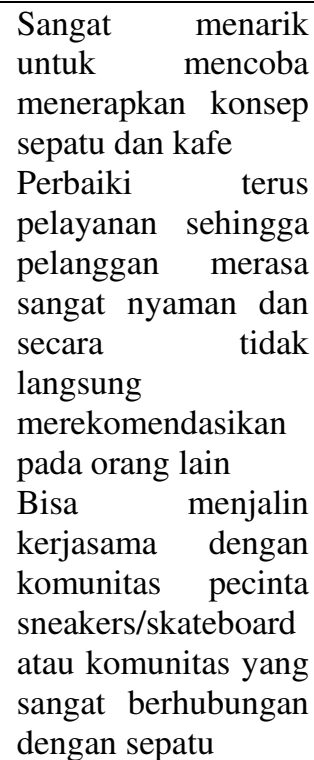 & $>$ & $\begin{array}{l}\text { Konsep yang } \\
\text { akan diterapkan } \\
\text { akan sangat } \\
\text { meramaikan } \\
\text { persaingan } \\
\text { dalam } \\
\text { perkembangan } \\
\text { kafe saat ini } \\
\text { Menyatukan dua } \\
\text { hal yang berbeda } \\
\text { dan saling } \\
\text { menguntungkan } \\
\text { sangat menarik } \\
\text { untuk dicoba }\end{array}$ & $\begin{array}{l}\text { Mau datang ke kafe } \\
\text { yang lebih } \\
\text { berkonsep, contoh } \\
\text { kafe di Jakarta yang } \\
\text { banyak memiliki } \\
\text { konsep seperti kafe } \\
\text { berkonsep penjara, } \\
\text { rumah sakit, lab dan } \\
\text { lain lain } \\
\text { Tertarik dengan kafe } \\
\text { berkonsep sepatu } \\
\text { yang menawarkan } \\
\text { kemudahan dalam } \\
\text { berbelanja }\end{array}$ \\
\hline 5 & $\begin{array}{c}\text { Apa yang } \\
\text { dikorbankannya } \\
\text { ? (pain) }\end{array}$ & & $\begin{array}{lr}\text { Biaya tambahan } \\
\text { untuk mendukung } \\
\text { konsep yang } \\
\text { diusung tetapi untuk } \\
\text { dua keuntungan } \\
\text { Konsep sepatu } \\
\text { sesuaikan dengan } \\
\text { konsep kafe jangan } \\
\text { sampai bertabrakan } \\
\text { Jangan lupakan taste } \\
\text { makanan }\end{array}$ & $>$ &  & $\begin{array}{l}\text { Bersedia membayar } \\
\text { lebih untuk konsep, } \\
\text { makanan dan } \\
\text { kenyamanan yang } \\
\text { diberikan lebih } \\
\text { Akan lebih tertarik } \\
\text { bila semua aspek } \\
\text { seimbang, konsep } \\
\text { matang, ambience } \\
\text { bagus, dan rasa } \\
\text { makanan yang enak }\end{array}$ \\
\hline 6 & $\begin{array}{c}\text { Apa yang } \\
\text { didapatkannya? } \\
\text { (gain) }\end{array}$ & & $\begin{array}{lr}\text { Pertumbuhan } & \\
\text { pelanggan } & \text { tentu } \\
\text { menjadi } & \text { target } \\
\text { utama saat } \\
\text { menerapkan } \\
\text { baru. } \\
\text { Kemsep } \\
\text { tingkat kepuasan } \\
\text { para pelanggan yang } \\
\text { meningkat. }\end{array}$ & & $\begin{array}{l}\text { Kemudahan } \\
\text { yang ditawarkan } \\
\text { harus semakin } \\
\text { terasa } \\
\text { Peningkatan } \\
\text { jumlah } \\
\text { pelanggan } \\
\text { Adanya ide-ide } \\
\text { baru akan terus } \\
\text { bermunculan } \\
\text { dalam bidang } \\
\text { bisnis ini di kota } \\
\text { seperti Bandung }\end{array}$ & 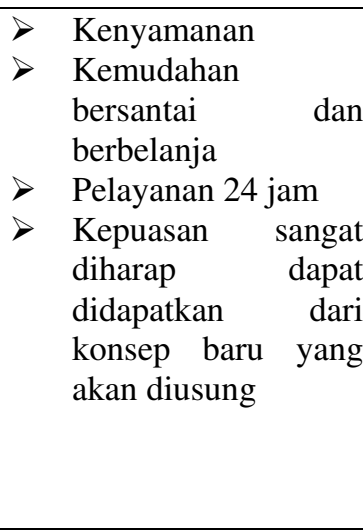 \\
\hline
\end{tabular}




\section{Peta Empati Campuran}

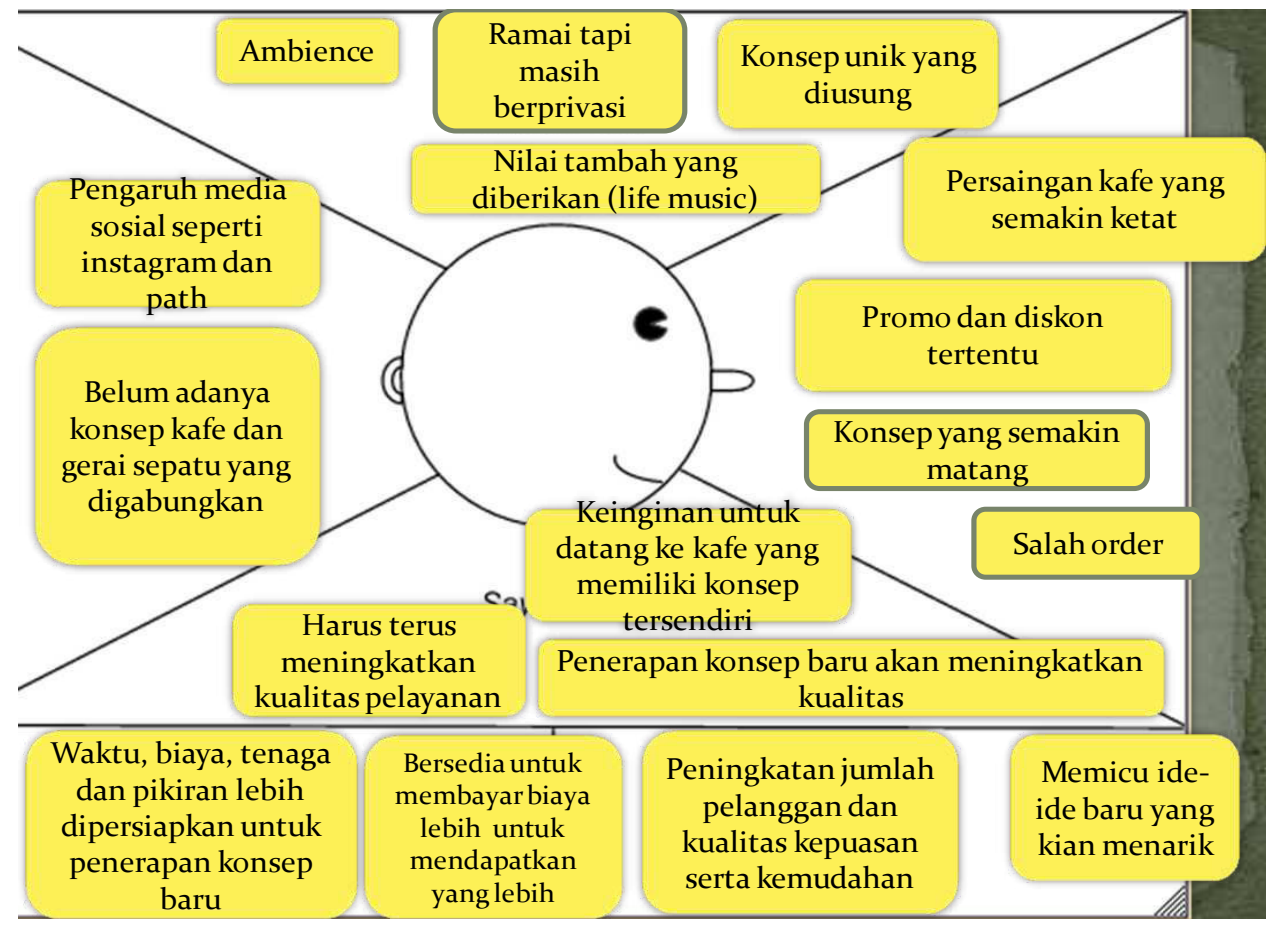

Gambar 7 Indikator Peta Empati

Pada indikator peta empati di atas dapat dikonfirmasi bahwa para pelanggan kafe saat ini mengharapkan suatu hal lebih yang dapat mereka rasakan dari pelayanan yang diterapkan kebanyakan kafe saat ini. Dengan kata lain, para pelanggan menginginkan adanya inovasi baru dari pelayanan kafe yang bertujuan untuk meningkatkan kualitas kepuasan dan sisi kemudahan sebuah layanan.

Dengan melihat dari hasil analisis indikator peta empati yang berasal dari para informan triangulasi, peneliti melihat terdapat adanya kebutuhan yang masih sedikit para praktisi usaha kafe yang menyadari kebutuhan tersebut.

\section{Model Bisnis Kanvas Zapateria shoes \& cafe}

Rancangan model bisnis Zapateria shoes \& cafe yang peneliti tetapkan adalah perencanaan konsep kafe dan gerai sepatu secara bersamaan, pemberian diskon-diskon tertentu dan kesediaan customer care website, serta didukung keramahan yang dijalin kepada para calon pelanggan diharapkan akan membangunkan tingkat kepuasan dan kepercayaan pelanggan terhadap Zapateria shoes \& cafe. Salah satu keunggulan dari Zapateria shoes \& cafe juga yakni penerapan sistem otomasi order dengan cara take order dengan gadget oleh waiters yang terintegrasi langsung pada sistem di kitchen sehingga mengurangi kemungkinan salah pesanan yang sering terjadi. Dari hal tersebut juga akan terbentuk kunjungan kafe yang bersifat terus-menerus sehingga menjadikan keramahan dan profesionalitas yang diberikan Zapateria shoes \& cafe tersampaikan dengan baik kepada para calon pelanggan. 
Ketersediaan sepatu sebagai barang dagangan bertujuan untuk mempermudah pelanggan dalam berwisata belanja dan mencoba berbagai menu makanan dunia serta free welcome drink yang disediakan. Pelanggan juga dapat membeli sepatu yang dijual Zapateria shoes \&cafe melalui website dan media sosial instagram, juga terdapat menu makanan pilihan dan penjelasan mengenai asal menu tersebut sehingga pelanggan bisa mendapatkan pengetahuan dari menu itu sendiri di dalam website yang dapat disantap langsung di kafe. Dari hal tersebut diharapkan pelanggan bisa mendapatkan kelebihan tersendiri yang belum pernah didapatkan di kafe lain dengan kenyamanan, fleksibilitas dan pengetahuan yang diberikan

\section{Model Bisnis Kanvas Zapateria shoes \& cafe}

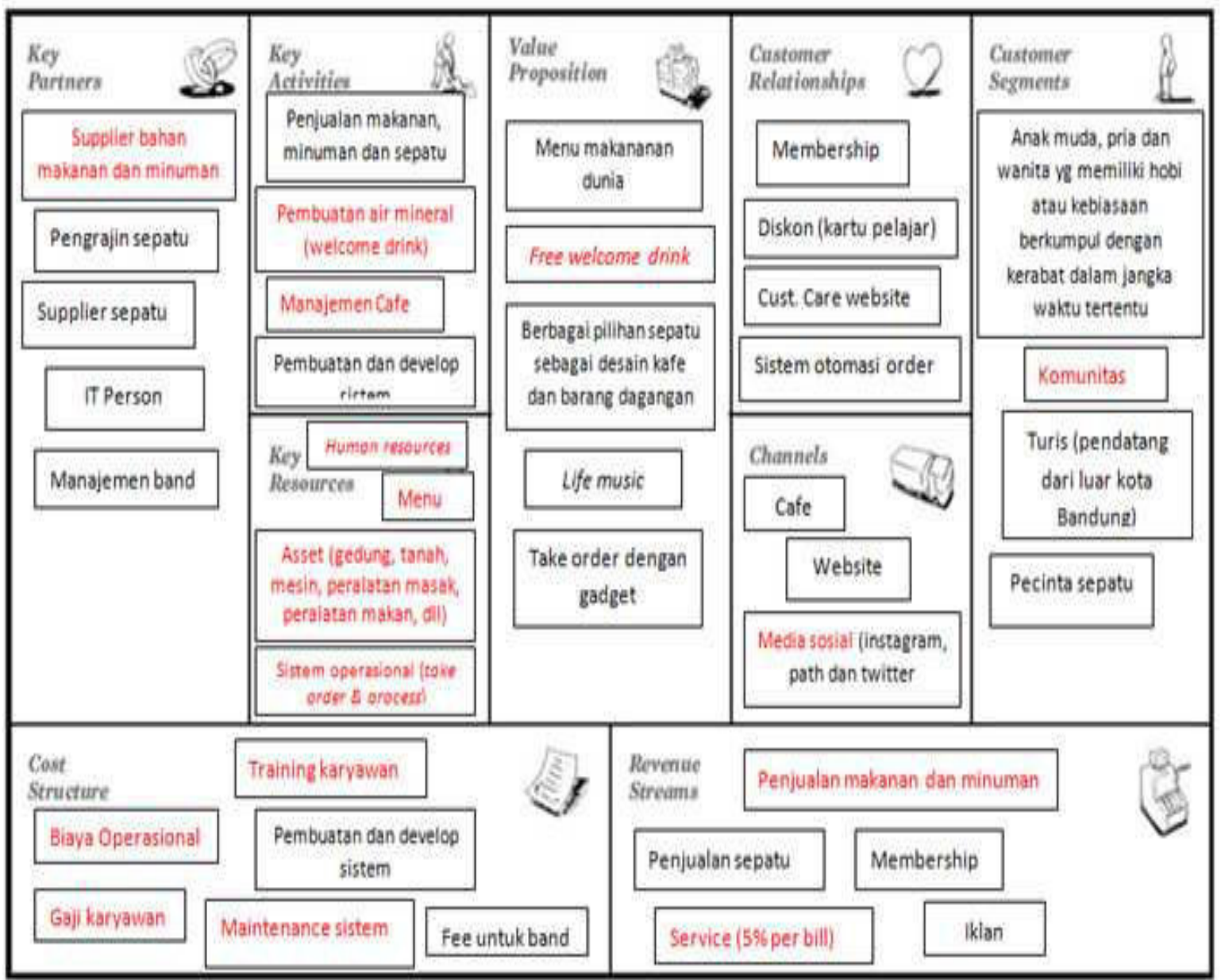

Gambar 8

Model Bisnis Kanvas Zapateria shoes \& cafe Fin

Sumber : data olahan penelit 


\section{SIMPULAN}

Kesimpulan Model Bisnis Kanvas Zapateria Shoes \& Cafe

\begin{tabular}{|c|c|c|}
\hline Blok & Hipotesis & Final \\
\hline $\begin{array}{l}\text { Segmen Pelanggan } \\
\text { (Customer Segments) }\end{array}$ & $\begin{array}{l}>\text { Anak muda, pria dan } \\
\text { wanita yang memiliki } \\
\text { hobi atau kebiasaan } \\
\text { berkumpul dengan } \\
\text { kerabat dalam jangka } \\
\text { waktu tertentu } \\
>\text { Komunitas } \\
>\text { Turis (pendatang dari } \\
\text { luar kota Bandung) } \\
>\text { Pecinta sepatu }\end{array}$ & $\begin{array}{l}>\text { Anak muda, pria dan } \\
\text { wanita yang memiliki } \\
\text { hobi atau kebiasaan } \\
\text { berkumpul dengan } \\
\text { kerabat dalam jangka } \\
\text { waktu tertentu } \\
>\text { Komunitas } \\
>\text { Turis (pendatang dari } \\
\text { luar kota Bandung) } \\
>\text { Pecinta sepatu }\end{array}$ \\
\hline $\begin{array}{c}\text { Proposisi Nilai (Value } \\
\text { Propositions) }\end{array}$ & $\begin{array}{l}>\text { Menu makanan dunia } \\
>\text { Free welcome drink } \\
>\text { Berbagai pilihan sepatu } \\
\text { sebagai desain interior } \\
\text { dan sekaligus barang } \\
\text { dagangan }\end{array}$ & $\begin{aligned} &> \text { Menu makanan dunia } \\
&> \text { Free welcome drink } \\
&> \text { Berbagai pilihan sepatu } \\
& \text { sebagai desain interior } \\
& \text { dan sekaligus barang } \\
& \text { dagangan } \\
&>\text { Life music } \\
&>\text { Take order dengan } \\
& \text { gadget }\end{aligned}$ \\
\hline Saluran (Channels) & $\begin{aligned} & \begin{array}{l}\text { Media sosial } \\
\text { (instagram, twitter dan } \\
\text { path) }\end{array} \\
> & \text { Kafe } \\
> & \text { Website }\end{aligned}$ & $\begin{aligned}> & \begin{array}{l}\text { Media sosial } \\
\text { (instagram, twitter dan }\end{array} \\
& \text { path) } \\
> & \text { Kafe } \\
> & \text { Website }\end{aligned}$ \\
\hline $\begin{array}{l}\text { Hubungan Pelanggan } \\
\text { (Customer Relationship) }\end{array}$ & $\begin{array}{l}>\text { Membership } \\
>\text { Diskon (student card) } \\
>\text { Customer care website }\end{array}$ & $\begin{array}{l}>\text { Membership } \\
>\text { Diskon (student card) } \\
>\text { Customer care website } \\
>\text { Sistem otomasi order }\end{array}$ \\
\hline
\end{tabular}




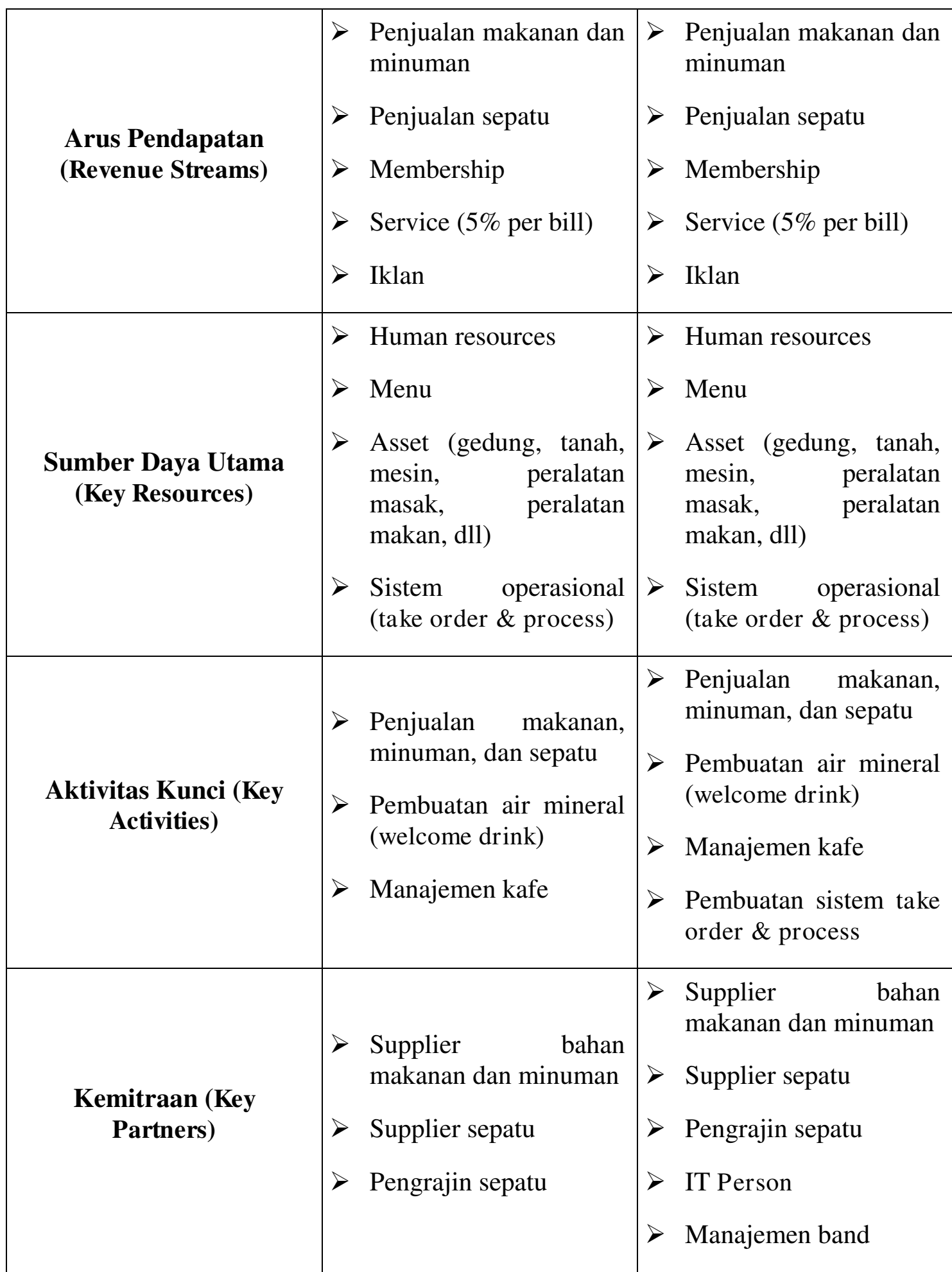




\begin{tabular}{|c|l|l|l|}
\hline & $>$ Biaya Operasional & $>$ Gaji karyawan \\
$\begin{array}{c}\text { Struktur Biaya (Cost } \\
\text { Structure) }\end{array}$ & $>$ Gaji karyawan & $>$ Training karyawan \\
& $>$ Training karyawan & $>$ Maintenance sistem \\
& $>$ Maintenance sistem & $>$ Pembuatan sistem take \\
& $>$ order \& process \\
& $>$ Fee band \\
\hline
\end{tabular}




\section{DAFTAR REFERENSI}

Arikunto, Suharsimi. (2006). Prosedur Penelitian - Suatu Pendekatan Praktik Edisi Revisi IV.Jakarta: Rieneka Cipta.

Creswell, John .W. (2009).Research Design: Pendekatan Kualitatif, Kuantitatif, dan Mixed. Yogyakarta: Pustaka Pelajar.

Creswell, John.W (2010). Research Design: pendekatan kualitatif, kuantitatif, dan mixed. Yogyakarta: Pustaka Pelajar.

Eisenmann, Thomas. (2002). Internet Business Models: Text and Cases. New York. McGrawHill/Irwin.

Narbuko, Cholid.,\& Achmadi, Abu. (2012). Metodologi Penelitian. Jakarta: PT Bumi Aksara.

Osterwalder, Alexander.,\& Pigneur, Yves. (2012). Business Model Generation.Jakarta: Elex Media Komputindo.

Sugiyono. (2012). Metode Penelitian Kuantitatif, Kualitatif dan R\&D. Bandung: Alfabeta.

Sugiyono, (2008). Metode Penelitian Kuantitatif Kualitatif dan R\&D. Bandung: Alfabeta

Suharyadi \& Purwanto.Statistika Untuk Ekonomi dan Keuangan Modern. (2009). Jakarta. Salemba Empat.

Susetyo, Budi. (2010). Statistika Untuk Analisis Data Penelitian. Bandung: Refika Aditama.

Taniredja, Tukiran.,\& Mustafidah, Hidayati. (2011). Penelitian Kuantitatif(Sebuah Pengantar). Bandung: Alfabeta.

http://bandung.go.id/images/download/8_BAB-I.pdf. Diakses pada tanggal 25 April 2014

http://bandungkota.bps.go.id/subyek/penduduk-2012. Diakses pada tanggal 17 Juni 


\section{BIODATA PENULIS}

Peggy Hariwan, SE., MT., MBA, memperoleh gelar Sarjana Ekonomi (SE), Jurusan Ekonomi Studi Pembangunan Universitas Tanjungpura, lulus tahun 1999. Memperoleh gelar Magister Teknik (MT) Program Pasca Sarjana Magister Teknik Institut Teknologi Bandung, lulus tahun 2003, gelar Master Business and Art Magister Groupe ESC Troyes Perancis tahun 2012 dan gelar Master of Science Universitas Padjadjaran tahun 2014. Saat ini menjadi Dosen Administrasi Bisnis Universitas Telkom Bandung.

Inggi Silviatni merupakan mahasiwa Administrasi Bisnis Universitas Telkom Bandung 